\title{
Biostimulation-phytoremediation of petroleum hydrocarbon contaminated soil: Response surface methodology (RSM)
}

Jing Li ( $\square$ 2283050052@qq.com )

UPC: China University of Petroleum Huadong

\section{Nian Ma}

China University of Petroleum Huadong

\section{Boyu Hao}

China University of Petroleum Huadong

\section{Feifei Qin}

China University of Petroleum Huadong

\section{Xiuxia Zhang}

China University of Petroleum Huadong https://orcid.org/0000-0002-3606-5952

\section{Research Article}

Keywords: Petroleum hydrocarbon degradation, Biostimulation-phytoremediation, Ecological restoration, Response surface methodology

Posted Date: April 28th, 2021

DOI: https://doi.org/10.21203/rs.3.rs-360082/v1

License: (c) (i) This work is licensed under a Creative Commons Attribution 4.0 International License. Read Full License 


\section{Abstract}

In view of the analysis and remediation of petroleum hydrocarbon contaminated soil, the study on ecological technology of oilfield well site was carried out. The response surface was used to optimize the single-factor biological stimulation experiment of moisture content, the leavening agent content and the compound fertilizer content, and get the best experimental plan of biological stimulation. The artificial stimulation-plant combined remediation experiment was designed. Through screening 20 kinds of plant seeds suitable for growth, selected 5 plants with high tolerance to petroleum hydrocarbons. The artificial biostimulation-phytoremediation combined degradation experiment of petroleum hydrocarbons in contaminated soil was designed, and the degradation rate of petroleum hydrocarbons in soil under the optimal ecological remediation scheme was obtained. It was found that petroleum hydrocarbons degradation rate in soil after 70 days artificial stimulation experiment was $28.6 \%$. Through the screening of 20 plants, peanut had the highest tolerance to petroleum hydrocarbons in soil, and the degradation rate in 70 days soil reached $31.1 \%$. After 70 days of biostimulationphytoremediation, the degradation rate in soil reached $38.9 \%$.

\section{Introduction}

As one of the important energy sources, petroleum has been widely used in the world. Total petroleum hydrocarbons (TPH) are one of the broadly existing organic pollutants in the environment. It is a mixture of various hydrocarbons (n-alkanes, branched alkanes, cycloalkanes, aromatics)(Rodriguez-Campos et al. 2019) and a small amount of other organic substances (sulfide, nitride, naphthenic acid, etc). Due to industrial activities such as the process of petroleum exploitation, storage, transportation, processing and petrochemical production, a large amount of petroleum enters into the environment and causes an increasing number of sites are severely contaminated(Kost et al. 2017; Prince et al. 2013; Varjani et al. 2017).

Petroleum hydrocarbon pollution has caused different degrees of impact on soil and groundwater environment. It is mainly manifested in the destruction of the structure and function of soil ecosystem. For example, it affects the permeability and the enzyme activity of the soil, resulting in soil hardening and fertility decline (Dindar et al. 2015). Further, the microbial biomass and bacterial population density decreased (Huang et al. 2019; Wu et al. 2020). In addition, petroleum hydrocarbon has lower density than water, so they have a tendency to float on the surface of surface water and groundwater and migrate or move easily with them flow to cause the groundwater pollution (Yang et al. 2020). Some teratogenic and carcinogenic substances in petroleum can also directly harm human health through bioaccumulation of food chain, and thus, effective measures should be taken immediately.

The treatment of contamination was caused by petroleum hydrocarbons is a huge and laborious work. In recent years, lots of in-situ and ex-situ remediation treatment methods and techniques have been researched and applied in the laboratory and on-site. These methods and techniques play a significant role in complete cleaning, containment, removal, reclamation and restoration of contaminated environment(Ossai et al. 2020). Petroleum contaminated soil treatment technology mainly includes physical remediation technology, chemical remediation technology and bioremediation technology, among which physical remediation technology is costly and difficult to operate; chemical repair technology is easy to damage soil structure, causing secondary soil pollution. It is imperative that we must find an effective technology to repair the contaminated soil. Bioremediation technology is considered an economical, efficient and green treatment method. They can remediate or degrade petroleum hydrocarbons and various organic contaminants to simpler and non-toxic substances without secondary pollution on the impacted environments(Lim et al. 2016).

There are many various ways of bioremediation technologies, including biostimulation, bioaugmentation, phytoremediation, animal repaired and microbe-assisted phytoremediation (Khoshkholgh Sima et al. 2019; Roy et al. 2018). Using bioaugmentation technology to increase the degradation rate of pollutants by introducing exogenous strains, this method tends to form a strong competition and predation relationship with indigenous microorganisms(Bidja Abena et al. 
2019). Therefore, the selection of indigenous microorganisms has been regarded as the first choice because they can easily acclimatize in the same environment(Suja et al. 2014). In order to overcome the limitations of local microorganisms by environmental factors such as temperature, oxygen, moisture content, $\mathrm{pH}$ and nutrients, many investigators have reported that biostimulation could be carried out by adding appropriate nutrients to increase the metabolic activity of microorganisms and accelerate the degradation of petroleum hydrocarbon contaminate(Gong 2012; Koshlaf et al. 2019; Margesin et al. 2003; Naidu et al. 2015; Wu et al. 2019). However, due to the complexity of oil contaminated sites, a single method cannot achieve the ideal treatment effect for petroleum hydrocarbon contaminated soil, so the integration of one remediation approach with another approach either simultaneously or sequentially may result in enhance the combined effect and degradation effect (Rippen 1999). Employing microbial-phytoremediation systems from soil is a novel, effective, and low-cost prospective biotechnological approach (Ni et al. 2018; Sarma et al. 2019). In the microbial-phytoremediation system, microorganisms convert pollutants such as petroleum hydrocarbons into substances that are easy for plants to directly absorb and utilize, and plant roots can provide suitable places for microorganisms to survive (Kiamarsi et al. 2020). In this system, the two can complement each other's advantages, thereby improving the repair ability. There are many examples of application of microbial-phytoremediation system at home and abroad(Fan et al. 2014; Kiamarsi et al. 2020; Wojtera-Kwiczor et al. 2014).

Only a few papers have reported a combination of biostimulation-phytoremediation. Accordingly, the objectives of this work as follows: (1) optimizing the single-factor (moisture content, the leavening agent content and the compound fertilizer content) biological stimulation experiment, (2) selecting plants with high tolerance to petroleum hydrocarbons, (3) designing the artificial biostimulation-phytoremediation combined remediation experiment. Therefore, the result of this study would provide valuable information for increasing the efficiency of TPH degradation rate.

\section{Materials And Methods}

\subsection{Materials}

The test soil used in this study was obtained from an oil field in Dongying, China. Prior to use, the soil was air-dried and stones, large soil particles and other debris were removed. The homogenized soil was then passed through a $4 \mathrm{~mm}$ sieve and the physicochemical properties of the contaminated soil was analyzed.The water used in the biological stimulation experiment was tap water, the leavening agent was broken corncobs with a particle size of about $1 \sim 2 \mathrm{~mm}$, and the compound fertilizer was agricultural fertilizer. The flowers and crop seeds used in the phytoremediation experiment were purchased from Dongying Farmers' Market. Beef cream agar medium (used to calculate the total number of bacteria): beef extract $5.0 \mathrm{~g}$, peptone $10.0 \mathrm{~g}$, sodium chloride $5.0 \mathrm{~g}$, agar $20.0 \mathrm{~g}$, deionized water $1.0 \mathrm{~L}, \mathrm{pH}$ 7.0-7.5. The reagents and drugs used in the experiment were analytical grade.

\subsection{Characteristics of soil}

The specific characteristics of the soil are presented in Table 1, the Petroleum content was $14.6 \mathrm{mg} / \mathrm{kg}$. The soil had a neutral $\mathrm{pH}$ (7.35). And they met the clean soil conditions used in the experiment. Also, the saturated content, aromatic content, colloid and asphaltene in oil were $42.89 \%, 23.91 \%, 20.42 \%$ and $1.55 \%$, respectively. The saturated and aromatic content is easy to degrade(Liu et al. 2020). There was a large saturated and aromatic fraction in the oil component, and it met the requirements of the biodegradation experiment. The soil used in subsequent experiments were all uniformly configured soils with a petroleum hydrocarbon content of $9000 \mathrm{mg} / \mathrm{kg}$. In addition, added the right amount of $\mathrm{NaNO}_{3}$ and $\mathrm{NaHPO}_{4}$ to make the ratio of C, N and P in the soil close to 100:10:1(Wu et al. 2014). By adjusting the CNP ratio, the degradation rate of petroleum hydrocarbons in the contaminated soil reached $9.1 \%$ and the total number of bacteria reached $9.1 \times 10^{3} \mathrm{CFU} / \mathrm{g}$ after 70 days experiment. The microorganisms in subsequent experiments were indigenous microorganisms. Due to the small particle size, poor nutrition and low water content of the tested soil, the three factors of 
moisture content, the leavening agent and the compound fertilizer were selected to provide the indigenous microorganisms with sufficient oxygen and nutrients required for growth and to optimize subsequent organisms Stimulus experiment.

Table 1 The physical and chemical properties of test soil

\begin{tabular}{|c|c|c|c|c|c|c|c|c|c|c|}
\hline & $\begin{array}{l}\text { Petroleum } \\
\text { content } \\
(\mathrm{mg} / \mathrm{kg})\end{array}$ & $\begin{array}{l}\text { moisture } \\
\text { content } \\
(\%)\end{array}$ & $\mathrm{pH}$ & $\begin{array}{l}\text { C } \\
(\mathrm{g} / \mathrm{kg})\end{array}$ & $\begin{array}{l}N \\
(\mathrm{~g} / \mathrm{kg})\end{array}$ & $\begin{array}{l}P \\
(\mathrm{~g} / \mathrm{kg})\end{array}$ & $\begin{array}{l}\text { Saturate } \\
\text { (『) }\end{array}$ & 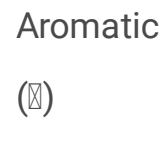 & $\begin{array}{l}\text { Resin } \\
(\bigotimes)\end{array}$ & $\begin{array}{l}\text { Asphaltenic } \\
\text { (『) }\end{array}$ \\
\hline sample & 14.6 & 9.29 & 7.34 & 47.43 & 4.26 & 0.3127 & 42.89 & 23.91 & 20.42 & 1.55 \\
\hline
\end{tabular}

\subsection{Experimental instruments}

Laboratory special ultra pure water machine, BCD-539WE refrigerator, UV-6000PC UV-Vis spectrophotometer, XS-204 electronic balance, LDZM vertical steam sterilization pot, HZQ-D water bath constant temperature oscillator,101-1A type electric heating blast drying oven, HSX-250 constant temperature and humidity incubator, intelligent electric heating constant temperature blast drying oven.

\section{Experimental Methods}

\subsection{Biological stimulation single factor experiment}

The experiments were conducted to investigate the effects of several factors (moisture content, the leavening agent content and the compound fertilizer content) on TPH degradation. As mentioned before, the addition of $\mathrm{NaNO}_{3}$ and $\mathrm{NaHPO}_{4}$ to soil with $9000 \mathrm{mg} / \mathrm{kg}$ in petroleum hydrocarbon content brings the proportion of C: $\mathrm{N}: \mathrm{P}$ in the soil close to 100:10:1. One kilogram of soil were taken and placed in a flower pot. The amount of moisture content was $10 \%, 15 \%, 20 \%, 25 \%$ and $30 \%$. The influence of the leavening agent content to TPH biodegradation was investigated by using different corn cob powder content set at $10 \mathrm{~g}, 30 \mathrm{~g}, 50 \mathrm{~g}, 70 \mathrm{~g}, 90 \mathrm{~g}$, respectively. And the compound fertilizer content was set at $10 \mathrm{~g}, 15 \mathrm{~g}, 20 \mathrm{~g}, 25 \mathrm{~g}, 30 \mathrm{~g}$, respectively. After fully stirring, the flower pots were placed in a thermostat and set the temperature to $25^{\circ} \mathrm{C}$. After 70 days, the petroleum hydrocarbon content in the soil was measured. All experiments were conducted in triplicate, and the average values are reported. The experiment set up a set of control groups.

The remaining petroleum hydrocarbons in the soil were used by ultrasonic extraction, the absorbance was measured at a wavelength of $225 \mathrm{~nm}$ using ultraviolet spectrophotometry, and the petroleum hydrocarbon content was calculated according to the standard curve. The specific steps were as follows: accurately weigh $0.1 \mathrm{~g}$ oily soil sample into a $50 \mathrm{~mL}$ centrifuge tube and add $10 \mathrm{~mL}$ petroleum ether (distillation range $60-90^{\circ} \mathrm{C}$ ). Extracted in ultrasonic for $15 \mathrm{~min}$, ultrasonic intensity: 360w (minimum 300w). Ultrasonic water bath temperature: select room temperature and control it below $40^{\circ} \mathrm{C}$. Centrifuge at $4000 \mathrm{r} / \mathrm{min}$ for $10 \mathrm{~min}$. The supernatant extract was collected into a $50 \mathrm{~mL}$ colorimetric tube through a glass long-diameter funnel containing $1 \mathrm{~cm}$ thick anhydrous sodium sulfate (baked at $500^{\circ} \mathrm{C}$ for $2 \mathrm{~h}$ ). These operations were repeated three times. Finally, the degradation rate calculation formula is as shown in formula (1).

$$
\text { Degradation rate }(\%)=\frac{W 0-W 1}{W 0} \times 100 \%
$$

$W_{0}$-initial petroleum content in soil, $\mathrm{g}$

$W_{1}$-petroleum residue in soil after 70 days of degradation, $\mathrm{g}$

\subsection{Biostimulation response surface optimization experiment design}


In this study, the single-factor biostimulation experiments was studied and optimized by using three factors, namely: moisture content $(A)$, the leavening agent content $(B)$ and the compound fertilizer content $(C)$. A rotatable $3^{k}$ Box-Behnken design (BBD) was adopted for the TPH degradation rate in 70 days are shown in table 2. The experimental results were analyzed using Design Expert 8.0.6 and a regression model was proposed using the diagnostic checking tests.

Table 2 Response surface experiment results

\begin{tabular}{|llllll|}
\hline Run order & A & B & C & \multicolumn{2}{c|}{ Degradation (\%) } \\
\cline { 5 - 6 } & & & & Actual & Predicted \\
\hline 1 & 10 & 30 & 20 & 15.3 & 15.2 \\
\hline 3 & 20 & 30 & 20 & 16.6 & 16.3 \\
\hline 4 & 10 & 70 & 20 & 17.8 & 18.2 \\
\hline 5 & 20 & 70 & 20 & 18.3 & 18.5 \\
\hline 6 & 10 & 50 & 15 & 17.7 & 17.8 \\
\hline 7 & 20 & 50 & 15 & 17.1 & 17.4 \\
\hline 8 & 10 & 50 & 25 & 17.3 & 17.0 \\
\hline 9 & 20 & 50 & 25 & 18.9 & 18.8 \\
\hline 10 & 15 & 30 & 15 & 17.5 & 17.5 \\
\hline 11 & 15 & 70 & 15 & 22.8 & 22.3 \\
\hline 12 & 15 & 30 & 25 & 19.5 & 20.0 \\
\hline 13 & 15 & 70 & 25 & 20.4 & 20.4 \\
\hline 14 & 15 & 50 & 20 & 29.6 & 28.9 \\
\hline 15 & 15 & 50 & 20 & 28.1 & 28.9 \\
\hline 16 & 15 & 50 & 20 & 27.6 & 28.9 \\
\hline & 15 & 50 & 20 & 29.5 & 28.9 \\
\hline 17 & & & & & 29.9 \\
\hline
\end{tabular}

\subsection{Phytoremediation experiment design}

The glass petri dishes with a diameter of $9 \mathrm{~cm}$ were chose, they were washed and sterilized at $110^{\circ} \mathrm{C}$ and put a layer of cotton inside, moistened it with distilled water and set aside. There were 20 plant seeds with 30 seeds each and put them in a petri dish covered with cotton. Then, added distilled water to make the water layer deep was $0.1 \mathrm{~cm}$. The test seeds were placed in a $25^{\circ} \mathrm{C}$ incubator for 14 days to observe the germination of the seeds. The germination rate of seeds was calculated by formula. After the plant seed germination rate experiment was completed, selected the plants with the highest germination rate for the tolerance experiment of petroleum contaminated soil. A petroleum contaminated soil with a concentration of $9000 \mathrm{mg} / \mathrm{kg}$ was configured, and $1 \mathrm{~kg}$ of soil was placed in a flower pot, and 3 seeds with a germination rate $\geq 90 \%$ were sow in each flower pot. The TPH degradation rate, the number of bacteria, the growth of test plants and the amount of catalase in the soil in the flowerpot were determined and calculated after 70 days of pot tests. All experiments were conducted in triplicate, and the average values were reported.

\subsection{Biostimulation-phytoremediation joint restoration experiment design}

Page 5/18 
Selecting the best biostimulation plan optimized by response surface methodology and the most dominant plants for joint restoration. The petroleum hydrocarbon content and the number of bacteria under the joint treatment soil every 10 days were measured.

\section{Results And Discussion}

\subsection{Factors affecting the biodegradation of the TPH degradation rate}

After 70 days of degradation, the degradation rate of petroleum hydrocarbons and the number of bacteria in the flowerpot soil were shown in Figure 1a. After 70 days of experimentation, it was found that when the moisture content was $15 \%$ into the soil, the degradation rate of petroleum hydrocarbons on the 70 th day was $9.4 \%$, it hardly improved the degradation effect. At the same time, the number of bacteria in the soil was $6.1 \times 10^{3} \mathrm{CFU} / \mathrm{g}$. Figure $1 \mathrm{~b}$ showed that the content of leavening agent had effect on the degradation of petroleum hydrocarbons by microorganisms, the degradation rate reached $18.4 \%$, a relative increase of $9.3 \%$. However, it had a greater impact on the total number of soil bacteria. The best amount of leavening agent was $50 \mathrm{~g}$. It could be explained with the following viewpoint, if the content of leavening agent was too small, the soil ventilation would also be small, and the normal respiration of microorganisms would be affected; if the content of leavening agent was too much, the living conditions of anaerobic organisms involved in the degradation of petroleum hydrocarbons would be affected. Figure 1c. showed that the degradation rate of petroleum hydrocarbons and the number of bacteria in the flowerpot soil after 70 days. It was concluded that when $20 \mathrm{~g}$ of compound fertilizer was added to the soil sample, the degradation rate of petroleum hydrocarbons in the soil was the largest, and the maximum degradation rate was $21.2 \%$. When $20 \mathrm{~g}$ of compound fertilizer was added to the soil sample, the number of bacteria in the soil was the highest, and the number of bacteria was at most $6.4 \times 10^{6} \mathrm{CFU} / \mathrm{g}$, relatively improved by three orders of magnitude.

\subsection{Optimization for biological stimulation experiment}

The experimental design and responses values of biological stimulation experiment were shown in Table 3 . As $P$ is less than 0.05 , the index has a significant impact, and if $P$ is less than 0.01 , the index is very significant. It can be seen from Table 3 that the $\mathrm{P}$ of the model is less than 0.0001 and the coefficient of the lack-of-fit term is greater than 0.05 , indicating that the model is of great significance for TPH bio-degradation. Use response surface software to perform binary regression fitting, and the regression equation obtained is as follows:

$$
\mathrm{Y}=28.94+0.35 \mathrm{~A}+1.30 \mathrm{~B}+0.12 \mathrm{C}-0.20 \mathrm{AB}+0.55 \mathrm{AC}-1.10 \mathrm{BC}-7.12 \mathrm{~A}^{2}-4.82 \mathrm{~B}^{2}-4.07 \mathrm{C}^{2}
$$

where $\mathrm{Y}$ represents the response variable (TPH degradation rate); $\mathrm{A}, \mathrm{B}, \mathrm{C}$ are the actual values of moisture content, the leavening agent content and the compound fertilizer content, respectively. The experimental results were subjected to analysis of variance (ANOVA) (Table 3). The model with calculated $F$ value and a very low $P$ value (less than 0.05$)$ showed that the model was highly significant (Karthic et al. 2013). In this experiment, the regression equation coefficient $R^{2}=0.9885$, the calibration determination coefficient $A d j R^{2}=0.9737>0.80$, the standard deviation Std. Dev. $=0.86$, and the coefficient of variation C.V.\%=4.01, indicating that the model fits well and the accuracy is high. Therefore, this empirical model can be applied to predict the TPH degradation rate. Also, the significant coefficients of the first-order coefficients $B$ and the quadratic coefficients $A^{2}, B^{2}, C^{2}$ are all less than 0.01 , and their influence were very significant, while the significant coefficients of the quadratic coefficients $B C$ was less than 0.05 , but greater than 0.01 , its impact was also significant. Comprehensive comparison shows that the significant impact on the degradation rate of petroleum hydrocarbons was: the leavening agent content $(B)<$ moisture content $(A)<$ the compound fertilizer content $(C)$. 
It can see from Fig. 2a, the model has a good fitting capability between the experimental values and the responses. The normal probability distribution of the residuals is on a straight line (Fig. 2b), indicating that the model has good adaptability. In addition, random dispersion of the residues and a distribution between -2 and +2 can also be seen in Fig.2c. To sum up, it was reasonable and acceptable for the regression model adequacy.

Table 3 Analysis of variance (ANOVA) for response surface quadratic model

\begin{tabular}{|lllllll|}
\hline Source & Sum of squares & Degree of freedom & Mean square & F-value & P-value prob $>$ F \\
\hline Model & 443.11 & 9 & 49.23 & 66.83 & $<0.0001$ & significant \\
\hline A & 0.98 & 1 & 0.98 & 1.33 & 0.2866 \\
\hline B & 13.52 & 1 & 13.52 & 18.35 & 0.0036 \\
\hline C & 0.13 & 1 & 0.13 & 0.17 & 0.6927 \\
\hline AB & 0.16 & 1 & 0.16 & 0.22 & 0.6554 \\
\hline AC & 1.21 & 1 & 1.21 & 1.64 & 0.2408 \\
\hline BC & 4.84 & 1 & 4.84 & 6.57 & 0.0374 \\
\hline A & 213.45 & 1 & 213.45 & 289.73 & $<0.0001$ \\
\hline$B^{2}$ & 97.82 & 1 & 97.82 & 132.78 & $<0.0001$ \\
\hline$C^{2}$ & 69.75 & 1 & 69.75 & 94.67 & $<0.0001$ \\
\hline Residual & 5.16 & 7 & 0.74 & & \\
\hline Lack of fit & 0.98 & 3 & 0.33 & 0.31 & 0.8152 \\
\hline Pure & 4.17 & 4 & 1.04 & & \\
\hline Cor Total & 448.27 & 16 & & & not significant \\
\hline
\end{tabular}

\subsection{Response surface plotting and optimization of bio-degradation process}

According to the quadratic equation model, the three-dimensional response surface and the contour map for the interaction between experimental factors were respectively made, and the interaction of the other two factors affects the degradation rate of TPH in a factor fixed in the same core value study, as shown in Figures 3.

When the model diagram is ellipse, indicating the interaction of factors is obvious, otherwise, it means that the interaction between the two factors is not significant(Sun et al. 2019). The contour map and 3D surface map of moisture content and the leavening agent content on the degradation rate of petroleum hydrocarbons are shown in Fig.3a below. It can be seen that the contour map of the interaction between moisture content and the leavening agent content on the degradation rate of petroleum hydrocarbons was almost circular. At this time, the degradation rate of petroleum hydrocarbons in the threedimensional surface map shows a trend of first increasing and then decreasing with the increase of leavening agent content, and the effect of water content on it is similar, indicating that there is no significant interaction between the two factors. Therefore, it shows that in the experimental soil at this time, there is no synergistic effect between moisture content and the leavening agent content.

Figure $3 \mathrm{~b}$ shows the effect of moisture content and the compound fertilizer content on the degradation rate of petroleum hydrocarbons, and there is an optimum point for moisture content at around $15 \%$. The degradation rate of petroleum hydrocarbons in the 3D surface graph first increases and then decreases with the amount of moisture content and the 
compound fertilizer content, indicating that there is no significant interaction between the amount of water sprayed and the amount of compound fertilizer.

In Fig.3c, the 3D pattern of leavening agent content was steeper than the contour line of the compound fertilizer content, indicating that the leavening agent content affected degradation rate more significantly(Antonopoulou et al. 2017). Under the leavening agent content of $30-50 \mathrm{~g}$, the degradation rate increased with the increase of addition. On the one hand, the function of leavening agent is to adjust the moisture and material porosity, increase soil oxygen content(Adhikari et al. 2009). On the other hand, it can be used as the regulation of soil nutrient composition to adjust the nutrient balance for the microbial community, so that the soil properties meet the needs of microbial growth and metabolism(Barrington et al. 2002). We also found that when the leavening agent content was about $50 \mathrm{~g}$, the compound fertilizer content was about 20 $\mathrm{g}$ slightly, the degradation rate reached the highest. It can be seen from Figure. 1c that the contour map is nearly oval, suggesting that there is a significant interaction between the two factors.

In summary of the three response surfaces, contour maps and regression equations, the best values of the three factors are $15 \mathrm{~mL}$ of moisture content, $50 \mathrm{~g}$ of leavening agent content, and $20 \mathrm{~g}$ of compound fertilizer content. The degradation rate of petroleum hydrocarbons predicted by the model under the optimal conditions of the three factors is $28.9 \%$. Under these optimal conditions, the experiment was conducted again to verify that the degradation rate of petroleum hydrocarbons within 70 days was $28.6 \%$, which is close to the model prediction results, and the accuracy of the model is better. Thus, it could be used to predict the effect of artificial stimulation to repair oil-contaminated soil. Studies have shown that biostimulation is the most successful and effective bioremediation method in simulated soil contaminated by petroleum hydrocarbons(Simpanen et al. 2016). The researchers used a mixture of bacterial consortia and nutrients to biodegrade petroleum hydrocarbon-contaminated soil within 18 months to achieve a 99.9\% removal rate(Singh et al. 2012). In contrast, the degradation effect of this study was not obvious, so the following joint plant restoration experiment was carried out.

\subsection{Dominant plant selection}

In order to explore phytoremediation of petroleum-contaminated soil, selected oil-tolerant plants, and improved the effect of on-site remediation of petroleum-contaminated soil. Twenty kinds of plants were selected for germination rate experiment. The germination rate of 8 kinds of seeds is $\geq 90 \%$ (Table 4), such as peanuts, shepherd's purse, zinnia, cotton, chives, beans, morning glory and Helianthus. The germination rate of the remaining 12 kinds of plant seeds is less than $80 \%$. It might be there are many factors that affect seed germination, and different seeds have different germination rates.

Table 4 Table of growth of tested plants 


\begin{tabular}{|c|c|c|c|c|}
\hline & Plant species & Number of tested seeds & Number of sprouted seeds & Germination rate/\% \\
\hline 1 & Cotton & 30 & 28 & 93.3 \\
\hline 3 & Soy & 30 & 22 & 73.3 \\
\hline 4 & Spinach & 30 & 12 & 40.0 \\
\hline 5 & Carob & 30 & 27 & 90.0 \\
\hline 6 & Lettuce & 30 & 0 & 0 \\
\hline 7 & Rape & 30 & 11 & 36.7 \\
\hline 8 & Chives & 30 & 28 & 93.3 \\
\hline 9 & Cabbage & 30 & 22 & 73.3 \\
\hline 10 & Shepherd's purse & 30 & 29 & 96.7 \\
\hline 11 & Strawberry & 30 & 23 & 76.7 \\
\hline 12 & Common China-aster & 30 & 0 & 0 \\
\hline 13 & Morning glory & 30 & 27 & 90.0 \\
\hline 14 & Bluebonnet & 30 & 5 & 16.7 \\
\hline 15 & Spearmint & 30 & 14 & 46.7 \\
\hline 16 & Clover & 30 & 0 & 0 \\
\hline 17 & Helianthus & 30 & 27 & 90.0 \\
\hline 18 & Callipsis & 30 & 16 & 53.3 \\
\hline 19 & Zinnia & 30 & 29 & 96.7 \\
\hline 20 & Eustoma & 30 & 0 & 0 \\
\hline
\end{tabular}

Five kinds of test seeds were selected and cultured in petroleum-contaminated soil for 70 days. The petroleum hydrocarbon content of the soil in the flowerpot was determined. After 70 days of exploration, the degradation rate of petroleum hydrocarbons in the soil by plants as shown in Fig. 4. Among the 5 tested plants, peanuts and cotton could germinate normally in the soil, and the degradation rates of TPH were $31.1 \%$ and $20.3 \%$, respectively. It might be that petroleum hydrocarbon pollution had not invaded the seed epidermis before seed germination and harmed the seed germ, so it showed that petroleum hydrocarbon pollution had little effect on seed germination and emergence. Because the experimental groups of shepherd's purse, zinnia and chives failed to germinate normally, their petroleum degradation was manifested as natural degradation. Plants can transform pollutants into environmentally less toxic and persistent substances through mechanisms such as phytoaccumulation, phytotransformation, rhizodegradation, phytostabilisation(Wang and Dai 2011). Peanut plants can remove organic pollutants in the soil through adsorption and accumulation, and the root exudates can complex and degrade organic pollutants, and the enzymes released by the roots into the soil also promote the degradation of pollutants(He et al. 2021).

The colony count could be considered as a method for the quantification of bacteria in soil. It might provide us with a useful insight regarding their growth in comparative studies. In the flowerpot where peanuts grew, the number of bacteria was the most, reaching $4 \times 10^{7} \mathrm{CFU} / \mathrm{g}$. In phytoremediation, peanuts plants affect the activities of microorganisms by changing the living environment of soil microorganisms, including changing water content, $\mathrm{pH}$, and releasing organic matter, transporting more nutrients for rhizosphere microorganisms, etc (Doornbos et al. 2012). In addition, peanuts have a larger root system, which provides a suitable habitat and sufficient oxygen for microorganisms. 
Enzyme activity is widely used to monitor soil pollution and remediation processes(A et al. 2020; Topac et al. 2009). The enzymes are used to monitor hydrocarbon degradation include lipase, dehydrogenase, catalase and urease, etc(Ueno et al. 2007).With the progress of restoration, soil catalase activity had a greater increasing trend. In the cultivation of peanut biological flowerpots, the content of catalase was the most, reaching $2.94 \mathrm{~mL} \otimes \mathrm{h}^{-1} \llbracket \mathrm{g}^{-1}$. Catalase activity could reflect the ability of the soil to remove the hydrogen peroxide produced during respiration. Catalase degrades hydrogen peroxide $\left(\mathrm{H}_{2} \mathrm{O}_{2}\right)$ into oxygen and water. If hydrogen peroxide has been accumulated but never decomposed, it will have a toxic effect on the microorganisms in the soil(Cristaldi et al. 2017; Hoang et al. 2021; Hussain et al. 2017).

\subsection{Biostimulation-phytoremediation of petroleum hydrocarbon contaminated soil}

The selected peanuts are combined with the best biological stimulation to treat petroleum-contaminated soil, and the TPH degradation rate in the soil under the combined situation is explored. As shown in Figure 5, the degradation rate of petroleum hydrocarbons in the soil reached $38.9 \%$ after 70 days. It contributes to the strong root system of peanuts. The introduction of peanuts provides better living conditions for bacteria and promotes bacterial growth. A large number of bacteria use petroleum hydrocarbons as nutrients, so petroleum hydrocarbons in the soil are degraded(Huang et al. 2014). After repairing $9000 \mathrm{mg} / \mathrm{kg}$, the residual petroleum hydrocarbons in the soil reached $5499 \mathrm{mg} / \mathrm{kg}$, which is far lower than the risk control value of $9000 \mathrm{mg} / \mathrm{kg}$ in the second type of construction land. This scheme can be used for on-site site restoration.

\section{Conclusions}

The present study was designed to explore and optimize the responses of biological stimulation experiment on petroleumcontaminated soil by response surface methodology, and combined with phytoremediation to enhance the effect of degradation and assist in setting up novel and highly efficient rhizoremediation systems. Through the response surface experiment design, under the best biological stimulation conditions, the experiment was conducted again to verify that the degradation rate of petroleum hydrocarbons within 70 days was $28.6 \%$. The degradation rate of individual peanut plants reached $31.3 \%$ after 70 days plant degradation experiments under natural conditions. After 70 days of biostimulationphytoremediation, the degradation rate of petroleum hydrocarbons in the soil reached $38.9 \%$ and the residual petroleum hydrocarbons in the soil reached $5499 \mathrm{mg} / \mathrm{kg}$. Exposing the peanut to petroleum pollution soil stimulated the root biomass and enzyme activity, concomitantly induced the biochemical and physiological responses in this plant. It is interesting to mention that the inoculation of bacterial consortium increased plant growth as well as hydrocarbon degradation. Therefore, the utilizing of peanut and specially the interaction of bacteria suggests an alternative strategy for effectual phytoremediation of soils contaminated with petroleum. The exact mechanisms and toxico-logical risk with the remediation process in this interaction and the possible effect of the polar fractions produced during the degradation process need further elucidation and also investigation.

\section{Declarations}

\section{Acknowledgement}

The authors sincerely thank the grant funded by the State Key Laboratory of Petroleum and Petrochemical Contaminant Control and Treatment. Support for the Open Project (authorization: PPC2019021), Research and promotion project of key technologies for safety and environmental protection of CNPC (2017D-4013) and the China Petroleum Technology Innovation Fund Research Project (authorization: 2017D-5007-0601, 2018D-5007-0605).

\section{Authors' contributions}

Jing Li: conceptualization and writing original draft; Nian Ma: methodology and investigation; Boyu Hao: experiental performance, conceptualization, methodology; Feifei Qin: material preparation, data collection and analysis; Xiuxia Zhang: 
project administration and funding acquisition.

\section{Funding}

The State Key Laboratory of Petroleum and Petrochemical Contaminant Control and Treatment. Support for the Open Project (authorization: PPC2019021), Research and promotion project of key technologies for safety and environmental protection of CNPC (2017D-4013) and the China Petroleum Technology Innovation Fund Research Project (authorization: 2017D-5007-0601, 2018D-5007-0605).

\section{Data availability}

All data and materials generated or analysed during this study are included in this published article.

\section{Compliance with ethical standards}

\section{Competing interests}

The authors declare that they have no conflict of interest.

\section{Ethics approval}

The authors confirm that the manuscript has been read and approved by all authors. The authors declare that this manuscript has not been published and not under consideration for publication elsewhere.

\section{Consent to participate}

The authors have been personally and actively involved in substantive work leading to the manuscript and will hold themselves jointly and individually responsible for its content.

\section{Consent for publication}

The authors consent to publish this research.

\section{References}

A VG, B GNK, A AB. 2020. Colonization by multi-potential Pseudomonas aeruginosa P4 stimulates peanut (Arachis hypogaea L.) growth, defence physiology and root system functioning to benefit the root-rhizobacterial interface. Journal of Plant Physiology 248.

Adhikari BK, Barrington S, Martinez J, Kinga S. 2009. Effectiveness of three bulking agents for food waste composting. Waste Management 29(1):197-203.

Antonopoulou M, Chondrodimou I, Bairamis F, Giannakas A, Konstantinou I. 2017. Photocatalytic reduction of $\mathrm{Cr}(\mathrm{VI})$ by char/TiO2 composite photocatalyst: optimization and modeling using the response surface methodology (RSM). Environmental Science and Pollution Research 24(2):1063-1072.

Barrington S, Choinière D, Trigui M, Knight W. 2002. Effect of carbon source on compost nitrogen and carbon losses. Bioresource Technology 83(3):189-194.

Bidja Abena MT, Li T, Shah MN, Zhong W. 2019. Biodegradation of total petroleum hydrocarbons (TPH) in highly contaminated soils by natural attenuation and bioaugmentation. Chemosphere 234:864-874. 
Cristaldi A, Conti GO, Jho EH, Zuccarello P, Ferrante M. 2017. Phytoremediation of contaminated soils by heavy metals and PAHs. A brief review. Environmental Technology \& Innovation 8:309-326.

Dindar E, Topaç Şağban FO, Başkaya HS. 2015. Variations of soil enzyme activities in petroleum-hydrocarbon contaminated soil. International Biodeterioration \& Biodegradation 105:268-275.

Doornbos RF, Loon LCV, Bakker PAHM. 2012. Impact of root exudates and plant defense signaling on bacterial communities in the rhizosphere. A review. Agronomy for Sustainable Development 32(1):227-243.

Fan YY, Wang GC, Fu JH, Zheng XH. 2014. The Remediation of Waste Drilling Muds by a Combined Plant-microbe System. Petroleum ence \& Technology 32(17):2086-2092.

Gong X. 2012. Remediation of weathered petroleum oil-contaminated soil using a combination of biostimulation and modified Fenton oxidation. International Biodeterioration \& Biodegradation 70:89-95.

He S, Chen Y, Xiang W, Chen X, Wang X, Chen Y. 2021. Carbon and nitrogen footprints accounting of peanut and peanut oil production in China. Journal of Cleaner Production 291:125964.

Hoang SA, Lamb D, Seshadri B, Sarkar B, Choppala G, Kirkham MB, Bolan NS. 2021. Rhizoremediation as a green technology for the remediation of petroleum hydrocarbon-contaminated soils. Journal of Hazardous Materials 401:123282.

Huang XF, Chaparro JM, Reardon KF, Zhang R, Shen Q, Vivanco JM. 2014. Rhizosphere interactions: root exudates, microbes, and microbial communities. Botany-botanique 92(92):281-289.

Huang Y, Pan H, Wang Q, Ge Y, Liu W, Christie P. 2019. Enrichment of the soil microbial community in the bioremediation of a petroleum-contaminated soil amended with rice straw or sawdust. Chemosphere 224:265-271.

Hussain I, Puschenreiter M, Gerhard S, Sch Ftner P, Yousaf S, Wang A, Syed JH, Reichenauer TG. 2017. Rhizoremediation of petroleum hydrocarbon-contaminated soils: Improvement opportunities and field applications. Environmental and Experimental Botany:S009884721730343X.

Karthic P, Joseph S, Arun N, Varghese LA, Santhiagu A. 2013. Biohydrogen production using anaerobic mixed bacteria: Process parameters optimization studies. Journal of Renewable \& Sustainable Energy 5(6):520.

Khoshkholgh Sima NA, Ebadi A, Reiahisamani N, Rasekh B. 2019. Bio-based remediation of petroleum-contaminated saline soils: Challenges, the current state-of-the-art and future prospects. Journal of Environmental Management 250:109476.

Kiamarsi Z, Kafi M, Soleimani M, Nezami A, Lutts S. 2020. Conjunction of Vetiveria zizanioides L. and oil-degrading bacteria as a promising technique for remediation of crude oil-contaminated soils. Journal of Cleaner Production 253:119719.

Koshlaf E, Shahsavari E, Haleyur N, Mark Osborn A, Ball AS. 2019. Effect of biostimulation on the distribution and composition of the microbial community of a polycyclic aromatic hydrocarbon-contaminated landfill soil during bioremediation. Geoderma 338:216-225.

Kost, David, Dick, Warren, A., Ye, Xiqiong, Li, Wei, Chen. 2017. Bioremediation of hydrocarbon degradation in a petroleum contaminated soil and microbial population and activity determination. Chemosphere Environmental Toxicology \& Risk Assessment.

Lim MW, Lau EV, Poh PE. 2016. A comprehensive guide of remediation technologies for oil contaminated soil - Present works and future directions. Marine Pollution Bulletin 109(1):14-45.

Page $12 / 18$ 
Liu Y, Chen S, Sheng L, Wang M, Liu HE. 2020. The phase behavior and solubilization ability of nonionic surfactantdistillate fraction of crude oil microemulsion system. Colloids and Surfaces A: Physicochemical and Engineering Aspects 603:125181.

Margesin R, Labbe D, Schinner F, Greer CW, Whyte LG. 2003. Characterization of Hydrocarbon-Degrading Microbial Populations in Contaminated and Pristine Alpine Soils. Applied and Environmental Microbiology 69(6):3085-3092.

Naidu, Ravi, Ramadass, Kavitha, Megharaj, Mallavarapu, Thavamani, Palanisami, Smith, Euan. 2015. Remediation trials for hydrocarbon-contaminated soils in arid environments: Evaluation of bioslurry and biopiling techniques. International Biodeterioration \& Biodegradation.

Ni N, Wang F, Song Y, Bian Y, Shi R, Yang X, Gu C, Jiang X. 2018. Mechanisms of biochar reducing the bioaccumulation of PAHs in rice from soil: Degradation stimulation vs immobilization. Chemosphere 196:288-296.

Ossai IC, Ahmed A, Hassan A, Hamid FS. 2020. Remediation of soil and water contaminated with petroleum hydrocarbon: A review. Environmental Technology \& Innovation 17:100526.

Prince RC, Mcfarlin KM, Butler JD, Febbo EJ, Wang FC, Nedwed TJ. 2013. The primary biodegradation of dispersed crude oil in the sea. Chemosphere 90(2):521-526.

Rippen G. 1999. Remediation of petroleum contaminated soils-biological, physical and chemical processesAutor: Eve RiserRoberts, PH. D. Umweltwissenschaften und Schadstoff-Forschung 11(6):352-352.

Rodriguez-Campos J, Perales-Garcia A, Hernandez-Carballo J, Martinez-Rabelo F, Hernández-Castellanos B, Barois I, Contreras-Ramos SM. 2019. Bioremediation of soil contaminated by hydrocarbons with the combination of three technologies: bioaugmentation, phytoremediation, and vermiremediation. Journal of Soils and Sediments 19(4):1981-1994.

Roy A, Dutta A, Pal S, Gupta A, Sarkar J, Chatterjee A, Saha A, Sarkar P, Sar P, Kazy SK. 2018. Biostimulation and bioaugmentation of native microbial community accelerated bioremediation of oil refinery sludge. Bioresource Technology 253:22-32.

Sarma H, Nava AR, Prasad MNV. 2019. Mechanistic understanding and future prospect of microbe-enhanced phytoremediation of polycyclic aromatic hydrocarbons in soil. Environmental Technology \& Innovation 13:318-330.

Simpanen S, Dahl M, Gerlach M, Mikkonen A, Malk V, Mikola J, Romantschuk M. 2016. Biostimulation proved to be the most efficient method in the comparison of in situ soil remediation treatments after a simulated oil spill accident. Environmental Science \& Pollution Research.

Singh B, Bhattacharya A, Channashettar VA, Jeyaseelan CP, Gupta S, Sarma PM, Mandal AK, Lal B. 2012. Biodegradation of Oil Spill by Petroleum Refineries Using Consortia of Novel Bacterial Strains. Bulletin of Environmental Contamination \& Toxicology.

Suja F, Rahim F, Taha MR, Hambali N, Rizal Razali M, Khalid A, Hamzah A. 2014. Effects of local microbial bioaugmentation and biostimulation on the bioremediation of total petroleum hydrocarbons (TPH) in crude oil contaminated soil based on laboratory and field observations. International Biodeterioration \& Biodegradation 90:115-122.

Sun S, Liu Q, Chen S, Yu W, Zhao C, Chen H. 2019. Optimization for microbial degradation of petroleum hydrocarbon (TPH) by Enterobacter sp. S-1 using response surface methodology. Petroleum science and technology 37(7):821-828.

Topac FO, Dindar E, Ucaroglu S, Baskaya HS. 2009. Effect of a sulfonated azo dye and sulfanilic acid on nitrogen transformation processes in soil. Journal of Hazardous Materials 170(2-3):1006-1013. 
Ueno A, Ito Y, Yumoto I, Okuyama H. 2007. Isolation and characterization of bacteria from soil contaminated with diesel oil and the possible use of these in autochthonous bioaugmentation. World Journal of Microbiology \& Biotechnology 23(12):1739-1745.

Varjani, Sunita, J. 2017. Microbial degradation of petroleum hydrocarbons. Bioresource Technology Biomass Bioenergy Biowastes Conversion Technologies Biotransformations Production Technologies.

Wang Y, Dai CC. 2011. Endophytes: a potential resource for biosynthesis, biotransformation, and biodegradation. Annals of Microbiology 61(2):207-215.

Wojtera-Kwiczor J, Ukowska W, Graj W, Ma Ecka A, Piechalak A, Ciszewska L, Chrzanowski U, Lisiecki P, Komorowicz I, Bara Kiewicz D. 2014. Rhizoremediation of Diesel-Contaminated Soil with Two Rapeseed Varieties and Petroleum degraders Reveals Different Responses of the Plant Defense Mechanisms. International Journal of Phytoremediation 16(7-8):770789.

Wu H, Zhang X, Bai X, Guo Y. 2014. Isolation and optimization degradation conditions of highly efficient degrading bacteria for oil-contaminated soil. Chinese Journal of Environmental Engineering 8:1229-1234.

Wu M, Ma C, Wang D, Liu H, Zhu C, Xu H. 2020. Nutrient drip irrigation for refractory hydrocarbon removal and microbial community shift in a historically petroleum-contaminated soil. Science of The Total Environment 713:136331.

Wu M, Wu J, Zhang X, Ye X. 2019. Effect of bioaugmentation and biostimulation on hydrocarbon degradation and microbial community composition in petroleum-contaminated loessal soil. Chemosphere 237:124456.

Yang Z, Verpoort F, Dong C, Chen C, Chen S, Kao C. 2020. Remediation of petroleum-hydrocarbon contaminated groundwater using optimized in situ chemical oxidation system: Batch and column studies. Process Safety and Environmental Protection 138:18-26.

\section{Figures}



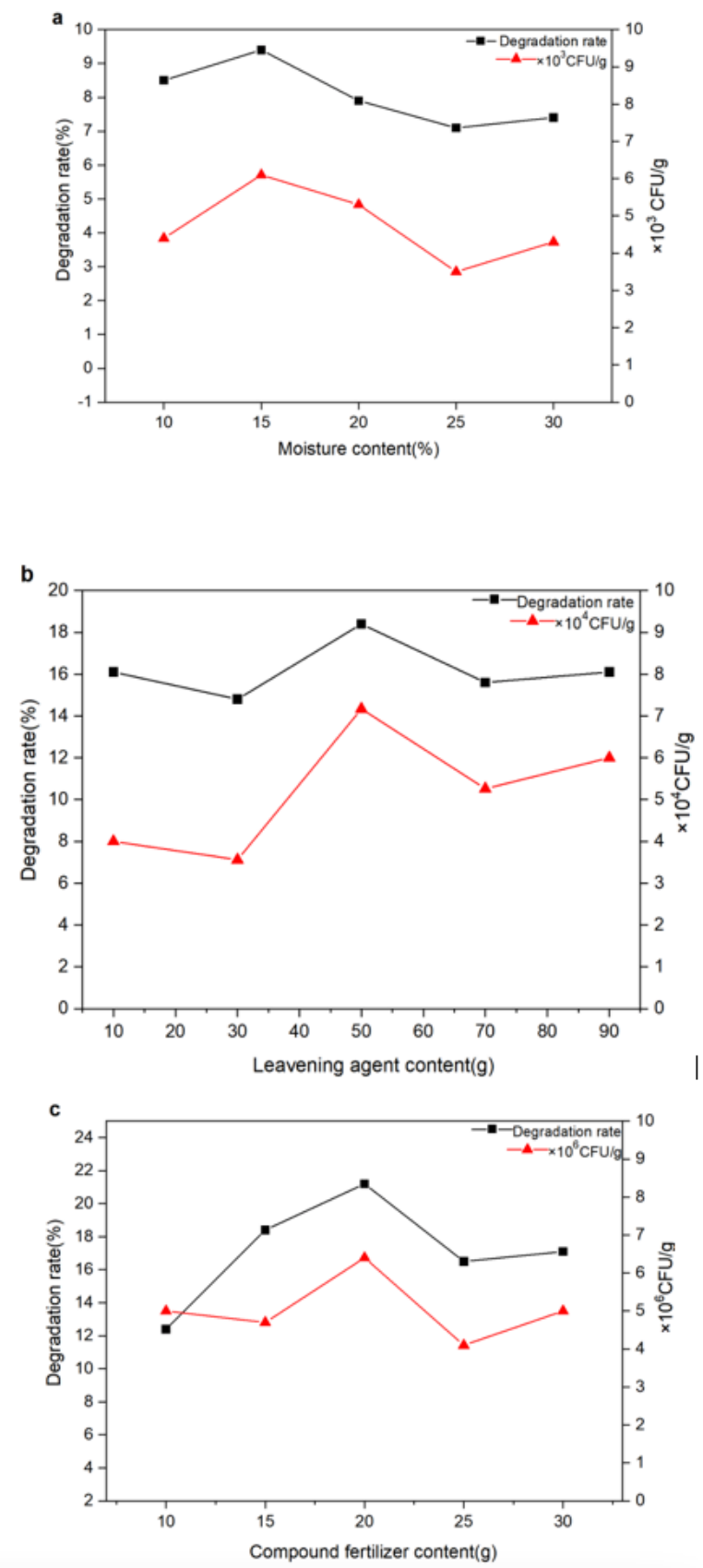

Figure 1

Factors affecting the biodegradation of the TPH degradation rate and the number of bacteria: $a$. the moisture content; $b$. the leavening agent content; $c$. the compound fertilizer content 
a
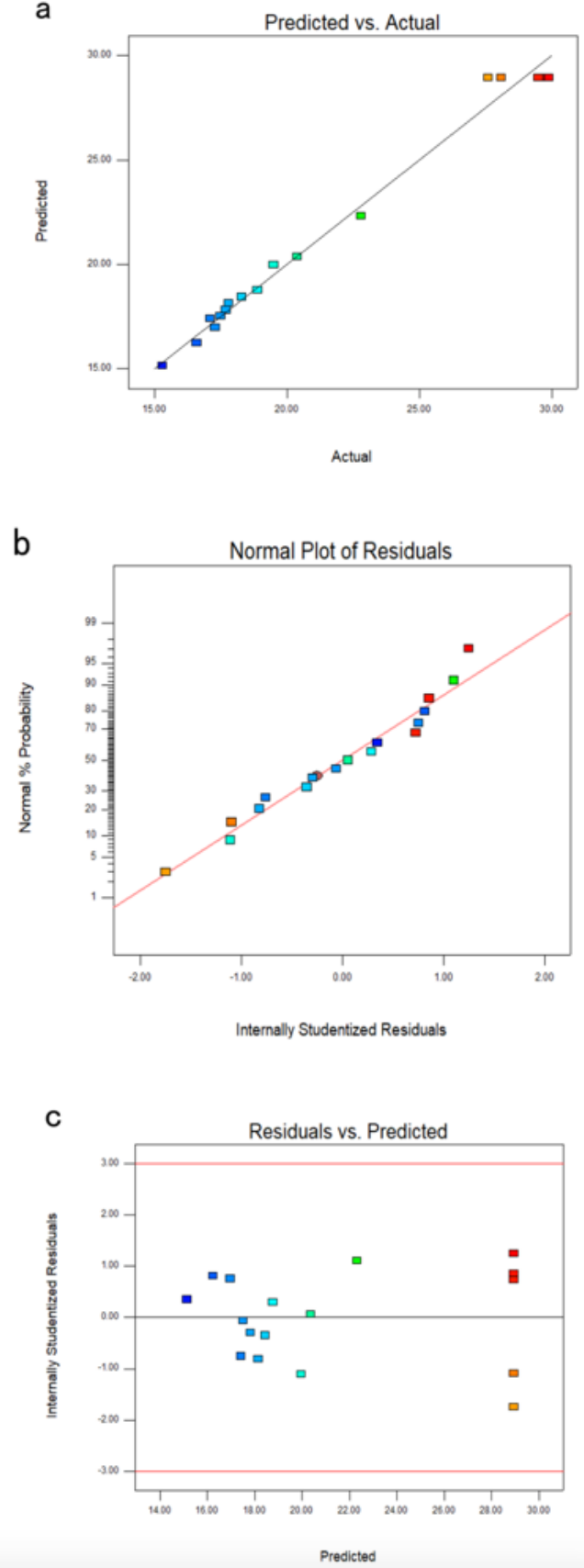

Figure 2

Residual diagnostics of quadratic model: a predicted vs. actual plot, b normal probability plot, and c internally studentized residuals vs. predicted values plot. 
a

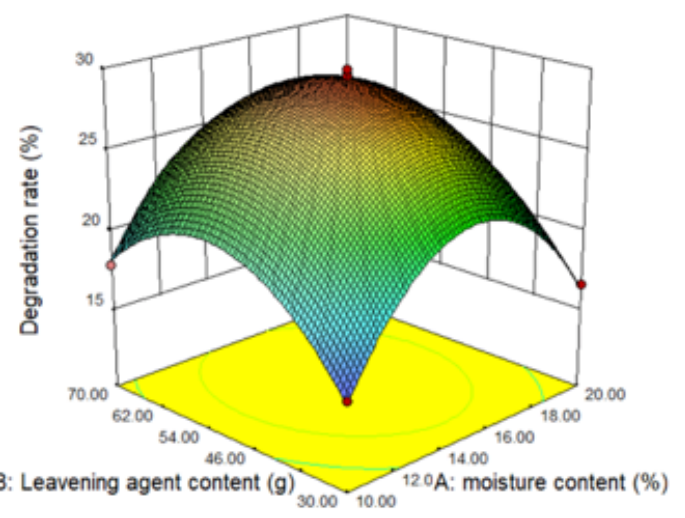

b
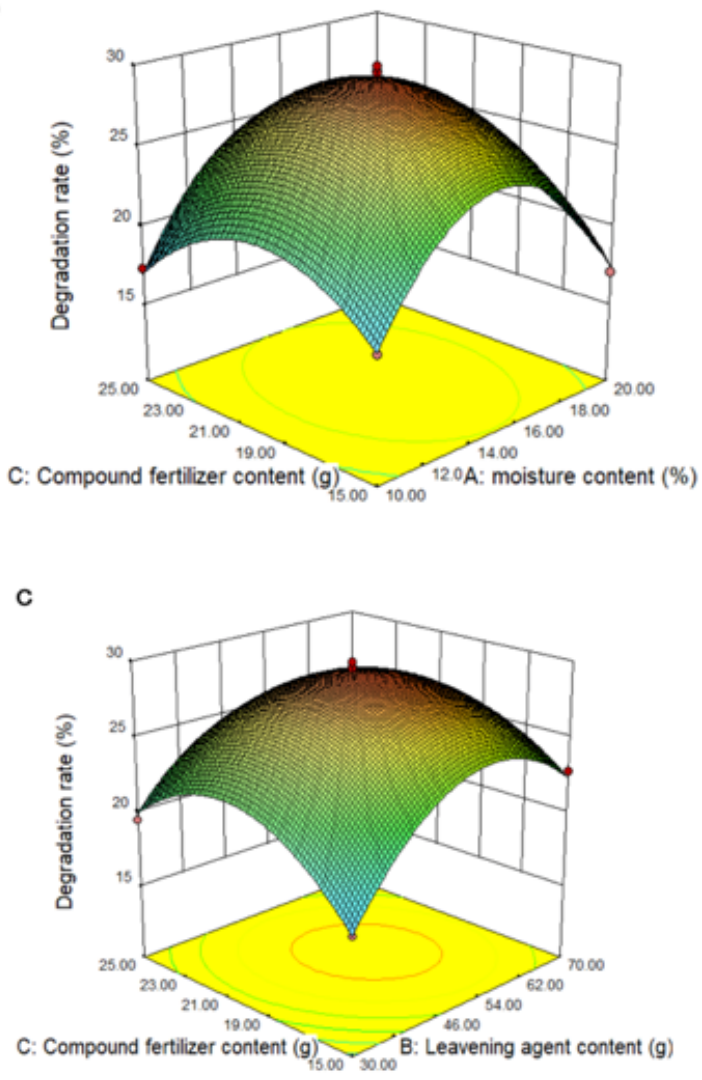
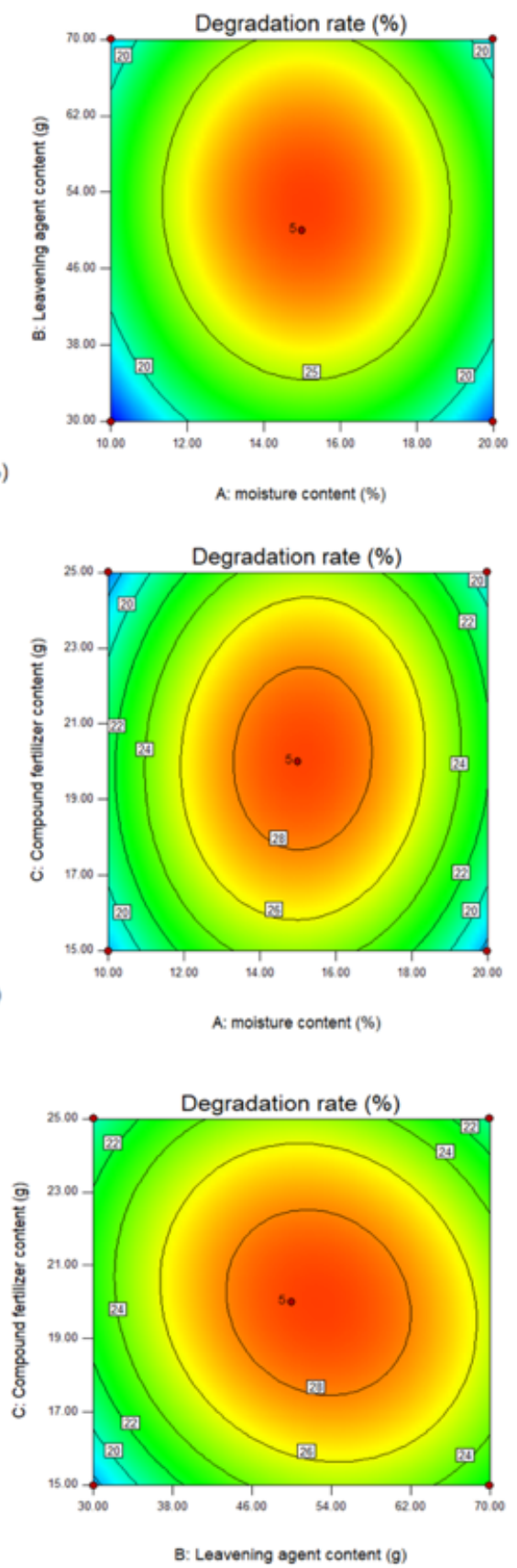

Figure 3

Three-dimensional response surface plots using RSM for TPH degradation rate: a moisture content vs. leavening agent content, b moisture content vs. compound fertilizer content, c compound fertilizer content vs. leavening agent content 


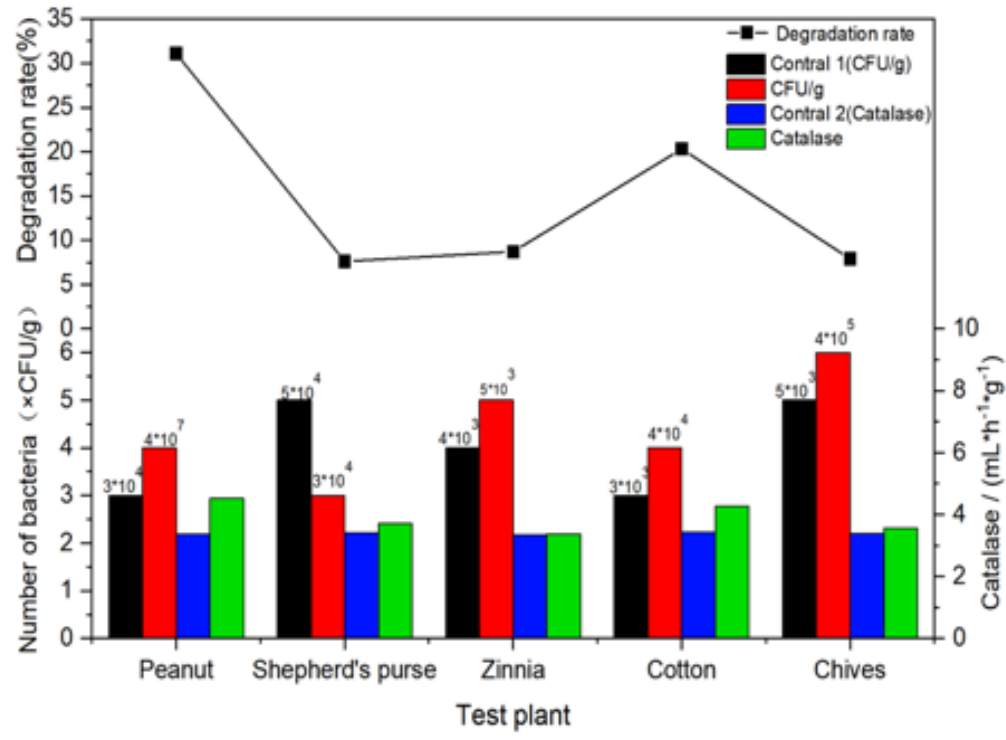

Figure 4

The degradation rate of petroleum hydrocarbons, the number of bacteria and the amount of catalase in 5 kinds of test plant soils

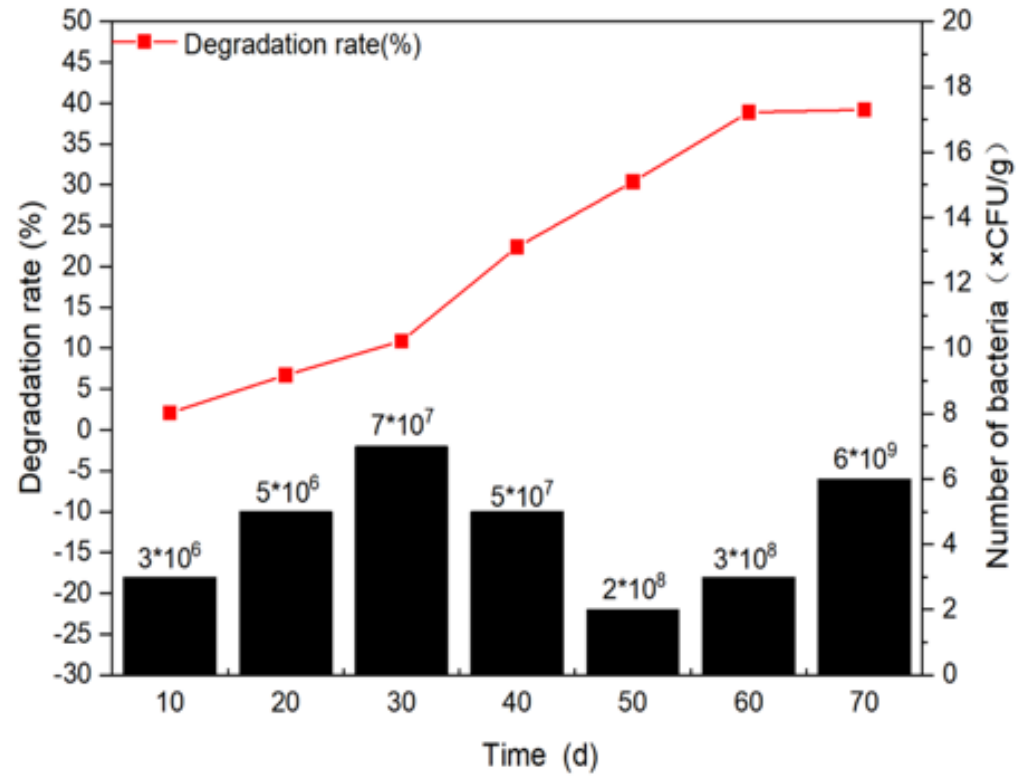

Figure 5

Joint Remediation of Oil Contaminated Soil 